\section{Injury Prevention: where to from here?}

\author{
Roderick J McClure
}

Injury Prevention publishes the science that defines our field. It is the signature publication supporting the primary, secondary and tertiary prevention of injury, for all people, from any cause. Accumulating in the pages of the Journal is a body of knowledge used across the world to improve the health of individuals and populations. The Journal's emphasis on primary prevention addresses the point in the prevention continuum with the greatest scope for minimising harm.

More than being simply an archive of information, the Journal is the intellectual charter that supports our field's currency and validity. Each issue contains the latest research findings judged by peers to be important contributions to knowledge. In editorials, commentaries and letters, contributors discuss approaches most likely to produce the best results. Established positions are revisited as we challenge and rejuvenate our beliefs. Injury Prevention is the voice of a constituency. The Journal is a forum we can all use to take collective responsibility for our field's future.

Ongoing editorial policy will encourage quality contributions from across the globe, in a mutually reinforcing relationship between the Journal and its growing readership, with view to improving the injury-related health of our global population. New editorial direction will focus the Journal's content on areas of importance and highlight issues that need more attention. The Journal will publish excellent, rigorously justified work that is relevant

Correspondence to Dr Roderick J McClure, Faculty of Medicine and Health, University of New England, Armidale, NSW 2351, Australia; rmcclure@une.edu.au and useful. By setting markers delineating our field and monitoring the field's progress, editors will encourage a purposive walk of scientific discovery towards impact on human health.

The Journal's new associate editors are six respected researcher-practitioners, from acclaimed institutes, from the world's far-flung corners. Together the associate editors will help set the Journal's strategic direction, grow the Journal's relevance to its international constituency and bring the best science to populations with the greatest injury burden. The senior editorial team now also includes six State of the Art Review (SOTAR) editors. Collectively, the SOTAR editors have over a century of injury leadership experience. The Journal will depend on the experience of this group to peg out territories of contemporary importance and thus generate forward momentum. Their commissioned reviews will encourage new research to fill identified gaps in the literature and facilitate use of best available evidence in prevention practice. The senior editor team will be well supported by an Editorial Board responsible for maintaining the high scientific standards of the Journal. Members of the Editorial Board are selected from among the Journal's best manuscript reviewers over the past 2 years, and will rotate through relatively short terms of office to allow new reviewers the opportunity to make their contributions. The social media editors will work on growing the Journal's engagement with its readership, and the statistical editor and two honorary editors will always be there to offer editorial wisdom when it is required.

The December 2017 issue of Injury Prevention was Dr Johnston's last as
Editor-in-Chief. While this introductory editorial is not the place to mark the full nature and extent of Dr Johnston's contribution to the Journal during his years at its helm, I would like, on behalf of us all, to offer my heartfelt thanks. Over many years, Dr Johnston expertly constructed the flagship journal that Injury Prevention has become. That Injury Prevention is characterised by its intellectual honesty, its courage and its influence is a direct consequence of these being the personal qualities of its departing Editor-in-Chief. I would also like to take this opportunity to thank the many members of past editorial team's.

So where to from here? The Journal is a communication platform, not a product. None of us knows what the world will look like in 10 years. We do know, though, that the problem of injury will remain, and so will the need for the Journal. As we start off, the new editorial team will aim to bring you the best science in the field, in the most immediate and usable way. Prevention, by definition, is forwardlooking. Many of you reading this issue are just starting out on your injury prevention careers with the future of the field of injury prevention in your hands. Thank you for stepping forward with the Journal into the possible world we choose to create.

\section{Competing interests None declared.}

Provenance and peer review Commissioned; internally peer reviewed.

(c) Article author(s) (or their employer(s) unless otherwise stated in the text of the article) 2018. All rights reserved. No commercial use is permitted unless otherwise expressly granted.

\section{Check for updates}

To cite McClure RJ. Inj Prev 2018;24:1

Inj Prev 2018;24:1.

doi:10.1136/injuryprev-2017-042695 